\title{
Acute Respiratory Failure in Obesity-Hypoventilation Syndrome Managed in the ICU
}

\author{
Nader Chebib, Pascale Nesme, Nathalie Freymond, Laurent Argaud, Thomas Rimmelé, \\ Julien Bohé, Gilles Devouassoux, Pierre-Jean Souquet, and Claude Guérin
}

\begin{abstract}
BACKGROUND: Obesity-hypoventilation syndrome (OHS) is defined as the combination of obesity (body mass index $\left.\geq 30 \mathrm{~kg} / \mathrm{m}^{2}\right)$ and daytime arterial hypercapnia $\left(\mathrm{P}_{\mathrm{aCO}}>45 \mathrm{~mm} \mathrm{Hg}\right)$ in the absence of other causes of hypoventilation, and can lead to acute hypercapnic respiratory failure in the ICU. Our objective was to describe the ventilatory management and outcomes of subjects with OHS who were admitted to the ICU for acute hypercapnic respiratory failure. METHODS: We retrospectively built a cohort of subjects with OHS who were admitted for acute hypercapnic respiratory failure in 4 ICUs of the university teaching hospital in Lyon, France, between 2013 and 2017. The main end point was the rate of success of noninvasive ventilation (NIV). Secondary end points were survival from OHS diagnosis to the last follow-up and risk factors for ICU admission and long-term survival. RESULTS: One hundred fifteen subjects with OHS were included. Thirtyseven subjects $(32.1 \%)$ were admitted to the ICU for acute hypercapnic respiratory failure. Congestive heart failure was the leading cause of acute hypercapnic respiratory failure (54\%). At ICU admission, $\mathrm{pH}$ before NIV use was median (range) 7.26 (7.22-7.31) and $\mathrm{P}_{\mathrm{aCO}}$ was $70(61-76) \mathrm{mm} \mathrm{Hg}$. NIV was used as first-line ventilatory support in 36 subjects $(97.2 \%)$ and was successful in 33 subjects $(91.7 \%)$. ICU mortality was low $(2.7 \%)$. The subjects admitted to the ICU were significantly older and had a lower $\mathrm{FEV}_{1}$ and vital capacity at the time of an OHS diagnosis. The difference in the restricted mean survival time was $663 \mathrm{~d}$ in favor of subjects not admitted to the ICU. Multivariate analysis showed that lower vital capacity at an OHS diagnosis was significantly associated with a higher risk of ICU admission. No factor was independently associated with long-term overall mortality in multivariate analysis. CONCLUSIONS: Acute hypercapnic respiratory failure in subjects with OHS was generally responsive to NIV and was frequently associated with congestive heart failure. Key words: obesity; obesity hypoventilation syndrome; acute respiratory failure; noninvasive ventilation; survival; intensive care unit. [Respir Care 2019;64(12):1545-1554. (C) 2019 Daedalus Enterprises]
\end{abstract}

\section{Introduction}

Obesity-hypoventilation syndrome (OHS) is defined as the combination of obesity (body mass index $[\mathrm{BMI}] \geq 30 \mathrm{~kg} / \mathrm{m}^{2}$ ) and daytime arterial hypercapnia

\footnotetext{
Drs Chebib and Guérin are affiliated with Réanimation Médicale Hôpital de la Croix Rousse, Hospices Civils de Lyon, Lyon, France. Drs Chebib, Argaud, Rimmelé, Bohé, Devouassoux, and Guérin are affiliated with Claude Bernard Lyon 1 University, University of Lyon, Lyon, France. Drs Nesme and Devouassoux are affiliated with Pneumologie Hôpital de la Croix Rousse, Hospices Civils de Lyon, Lyon, France. Drs Freymond and Souquet are affiliated with Pneumologie Centre Hospitalier Lyon Sud, Hospices Civils de Lyon, Lyon, France. Dr Argaud is affiliated with Réanimation Médicale Hôpital Edouard Herriot, Hospices Civils de Lyon,
}

$\left(\mathrm{P}_{\mathrm{aCO}_{2}}>45 \mathrm{~mm} \mathrm{Hg}\right)$ in the absence of other causes of chronic hypoventilation, such as obstructive or restrictive lung disease. ${ }^{1}$ The prevalence of obesity has been progressively increasing worldwide over the past few decades. ${ }^{2-4}$ The World Health Organization estimates an obesity prevalence rate of $13 \%$ among adults, with

\footnotetext{
Lyon, France. Dr Rimmelé is affiliated with Anesthésie et Réanimation Médicale Hôpital Edouard Herriot, Hospices Civils de Lyon, Lyon, France. Dr Bohé is affiliated with Réanimation Médicale Centre Hospitalier Lyon Sud, Hospices Civils de Lyon, Lyon, France. Dr Guérin is affiliated with IMRB (Institut Mondor de Recherche Biomédicale) INSERM (Institut National de la Santé et de la Recherche Médicale) 955 Créteil and Médecine Intensive et Réanimation, Centre Hospitalier Universitaire Grenoble, Grenoble, France.
} 


\section{Acute Respiratory FaIlure IN OHS}

major sociodemographic variations (http://www.who.int/ news-room/fact-sheets/detail/obesity-and-overweight. Accessed December 16, 2018). As a result, OHS is an increasing cause of acute hypercapnic respiratory failure, defined as the combination of clinical signs of respiratory failure and respiratory acidosis $(\mathrm{pH}<7.35$ and $\mathrm{P}_{\mathrm{aCO}_{2}}>45 \mathrm{~mm} \mathrm{Hg}$ ) that requires admission to the ICU. Epidemiological studies reported a 9 to $50 \%$ prevalence range of obesity in subjects admitted to the ICU. ${ }^{5-7}$ However, OHS remains underrecognized in the ICU setting. Noninvasive ventilation (NIV) has been clearly established as the standard of care in subjects with acute respiratory failure from COPD and cardiogenic pulmonary edema. ${ }^{8-11}$

Early studies have demonstrated NIV to be beneficial in treatment of respiratory failure in immunocompromised subjects. ${ }^{12,13}$ In patients with OHS, NIV is also recommended as a first-line therapy in this setting. ${ }^{14}$ However, data with regard to the management of OHS in the ICU are limited. NIV use in patients with OHS may be challenging for various reasons, such as the potential for improper interface fit to anatomic features (large face, short and enlarged neck), the misuse in ventilator settings due to the large discrepancy between actual and predicted body weight, and upper-airway obstruction from the associated obstructive sleep apnea syndrome (OSAS) that should make PEEP higher than in other situations. Our objective was to describe the ventilatory management and the outcome of subjects with OHS admitted to the ICU for acute hypercapnic respiratory failure.

\section{Methods}

\section{Study Population}

A retrospective study was conducted in 4 ICUs, with 2 pneumology and sleep laboratory departments taking part at the tertiary university teaching hospital in Lyon, France. The third pneumology department in this institution was not included because it did not manage patients with sleep-disordered breathing and/or those who required long-term ventilatory support. Each participating pneumology department had a capacity of 42 beds and an annual admission rate of nearly 2,400 patients over the study period, and was staffed with 7 senior physicians. Each

\section{The authors have disclosed no conflicts of interest.}

Correspondence: Nader Chebib MD, Service de Réanimation Médicale, Hôpital de la Croix Rousse, 103 Grande rue de la Croix rousse, 69004 Lyon, France. E-mail: nader.chebib@chu-lyon.fr.

DOI: $10.4187 /$ respcare. 06901

\section{QUICK LOOK}

\section{Current knowledge}

The prevalence of obesity is increasing worldwide and is considered a public health issue. OHS is a cause of acute hypercapnic respiratory failure and requires admission to the ICU. Noninvasive ventilation is recommended as a first-line therapy for acute hypercapnic respiratory failure in patients with OHS. However, recent data with regard to epidemiology, ventilatory management, and outcomes of OHS in the ICU are limited.

\section{What this paper contributes to our knowledge}

During the course of OHS, ICU admission for acute hypercapnic respiratory failure was frequent. Congestive heart failure was a common precipitating factor. OHS was largely underrecognized in medical wards before ICU admission. Noninvasive ventilation was highly successful in preventing intubation or death despite the delayed response in correcting hypercapnic acidosis. Vital capacity at OHS diagnosis was a novel surrogate marker for OHS severity and was associated with ICU admission.

participating ICU had a capacity of 15 beds, admitted $\sim 900$ patients per year and was staffed with 7 senior physicians.

The present cohort was built as follows. First, the files of patients with OHS who were hospitalized at least once between January 1, 2013, and September 30, 2017, in either pneumology ward were retrieved. Patients either had an OHS diagnosis before January 1, 2013, or were newly diagnosed with OHS during the study, with the date of OHS diagnosis subsequently recorded. During the hospitalization in the pneumology wards, a thorough diagnostic workup for OHS was made, including chest computed tomography, pulmonary function tests, overnight polygraphy and/or polysomnography, and arterial blood gas determination (morning and daytime samples).

Inclusion criteria were the following: age $\geq 18 \mathrm{y}$; acute hypercapnic respiratory failure, defined as the presence of clinical signs of respiratory failure, together with respiratory acidosis $\left(\mathrm{pH}<7.35\right.$ and $\left.\mathrm{P}_{\mathrm{aCO}_{2}}>45 \mathrm{~mm} \mathrm{Hg}\right)$, and the need of ventilatory support to reverse clinical signs of acute hypercapnic respiratory failure and/or correct hypercapnic acidosis; and OHS diagnosis before or after ICU admission. For subjects with multiple ICU admissions, data from the first admission were analyzed. Exclusion criteria included ICU admission for other causes of acute hypercapnic respiratory failure, such as septic or hemorrhagic shock. 


\section{Acute Respiratory FaIlure IN OHS}

\section{Study End Points}

The primary end point was the rate of NIV success in the management of acute hypercapnic respiratory failure in the subjects with OHS admitted to the ICU. NIV failure was defined as the need for endotracheal intubation or death during the ICU stay. The secondary end points were ICU mortality, ICU and hospital lengths of stay, time to correct hypercapnic acidosis with NIV (defined as an increase of $\mathrm{pH}$ to 7.35-7.45, together with any decrease of $\mathrm{P}_{\mathrm{aCO}}$ ), long-term survival, identification of factors associated with ICU admission and with mortality at the last follow-up, and the association of ICU admission with mortality at the final follow-up.

A dedicated case record form was used for the included subjects to collect the following: (1) clinical, functional, biological, and OHS treatment characteristics at the time of the first hospitalization in the pneumology ward; (2) clinical data and management during the ICU stay; and (3) subject outcomes. The database was anonymous and complied with the requirements of our university teaching hospital's Commission Nationale de l'Informatique et des Libertés, the organization that regulates the collection, storage, and use of personal data (study registration 18-274). In accordance with French legislation, our observational study did not require written consent from the subjects. However, we sought to obtain the non-refusal of the included subjects by sending them a written letter explaining the modalities and purposes of our study. The study was approved by the ethical committee of our university teaching hospital (Hospices Civils de Lyon). This study was performed in Hospices Civils de Lyon, a tertiary university teaching hospital in Lyon, France.

\section{Statistical Analysis}

The normal distribution of variables was assessed by using Kolmogorov-Smirnov and Shapiro-Wilk tests. Quantitative variables were expressed as median with first and third quartiles, and were compared by using the MannWhitney test. Qualitative variables were expressed as count and percentage, and were compared by using the chi-square test or the Fisher exact test when necessary. The probability of survival was estimated by using the Kaplan-Meier method. The point of time was set on October 1, 2017. The log-rank test was used to compare the probability of survival in subjects with and without ICU admission. We also computed the difference in the restricted mean survival time at the last follow-up between the subjects with and without an ICU stay. The difference in the restricted mean survival time was the area between Kaplan-Meier graphs. A logistic regression model was used to analyze factors associated with ICU admission. Variables associated with ICU admission in the univariate analysis with $P<.20$ were used as covariates in the multivariate logistic regression analysis.

The Cox proportional hazard model was used to analyze factors associated with mortality at the last follow-up. The proportionality assumption was assessed by creating a Cox model with time-by-covariate interactions for each variable (introducing products between the variables and a linear function of time) and by testing for statistical significance. Variables associated with overall mortality in the univariate analysis with $P<.20$ and exhibiting constant relative hazard over time were used as covariates in the model. A stepwise logistic regression analysis was then performed. To further analyze the role of ICU admission on long-term survival, we reasoned that a ICU stay was a competitive factor and defined 3 transitions (OHS onset to ICU admission, OHS onset to last follow-up, and ICU admission to last follow-up). We checked the proportionality of risk for each transition and then investigated whether the time a subject arrived to the ICU admission stage influenced the subsequent death; this was the transition hazard from ICU admission to death. We finally performed a time-dependent Cox proportional model in which the ICU stay was the time-dependent covariate. Statistical analysis was performed with SPSS Statistics 21 software (IBM, Armonk, New York) and with mstate, survival and survRM2 packages of $\mathrm{R}$ software version 3.2 (R, R Foundation for Statistical Computing, Vienna, Austria, URL http://www.R-project.org/. Accessed October 28, 2018). $P<.05$ was considered statistically significant.

\section{Results}

\section{OHS Population}

Between January 1, 2013, and September 30, 2017, 115 subjects with OHS were included (Table 1). No subject was admitted to the ICU before January 1, 2013, or was admitted to any ICU (other than the 4 study ICUs) during the study. Age was median (range) $69(60-76)$ y and BMI of $42(37-48) \mathrm{kg} / \mathrm{m}^{2}$. Female sex was largely predominant (77\%), and $72 \%$ of the subjects had a concurrent OSAS. Daytime $\mathrm{P}_{\mathrm{aCO}_{2}}$ at the time of an OHS diagnosis was median (range) 49 (47-53) $\mathrm{mm} \mathrm{Hg}$. After an OHS diagnosis, 89 subjects $(77.4 \%)$ were treated with long-term NIV and $18.4 \%$ with CPAP. During the median follow-up period of median (range) 3.5 (1.4-6) y, 20 subjects (17.4\%) died of respiratory failure due to OHS as the cause of death in 6 subjects $(5.2 \%)$. Nine of these subjects were admitted to the ICU. Survival rates at 1, 3, and 5 y were 99, 91.6, and $80.4 \%$, respectively.

\section{Subjects With OHS Admitted to the ICU}

During the follow-up period, 37 subjects $(32.1 \%)$ were admitted to the ICU for acute hypercapnic respiratory failure 


\section{Acute Respiratory Failure in OHS}

Table 1. Clinical, Functional, and Treatment Characteristics of the Subjects With OHS

\begin{tabular}{|c|c|c|c|c|}
\hline \multirow[b]{2}{*}{ Characteristic } & \multicolumn{3}{|c|}{ OHS } & \multirow[b]{2}{*}{$P$} \\
\hline & $\begin{array}{l}\text { Overall Population } \\
\quad(N=115)\end{array}$ & $\begin{array}{l}\text { Without ICU Admission } \\
\qquad(n=78)\end{array}$ & $\begin{array}{l}\text { With ICU Admission } \\
\qquad(n=37)\end{array}$ & \\
\hline Age at diagnosis, median (range) y & $69(60-76)$ & $67(58-75)$ & $71(65-78)$ & .02 \\
\hline Female-to-male ratio & 3.4 & 3.8 & 2.7 & .43 \\
\hline BMI, median (range) $\mathrm{kg} / \mathrm{m}^{2}$ & $42(37-48)$ & $42(37-48)$ & $41(35-47)$ & .11 \\
\hline Smoking status & & & & .14 \\
\hline Non-smoker, $n(\%)$ & $89(77.4)$ & $63(80.7)$ & $26(70.3)$ & NA \\
\hline Active smoker, $n(\%)$ & $12(10.4)$ & $6(7.6)$ & $6(16.2)$ & NA \\
\hline Former smoker, $n(\%)$ & $14(12.2)$ & $9(11.5)$ & $5(13.5)$ & NA \\
\hline Pack-years, median (range) & $30(10-30)$ & $17(10-37)$ & $34(20-50)$ & .11 \\
\hline \multicolumn{5}{|l|}{ Comorbidities } \\
\hline Charlson score, median (range) & $1(1-2)$ & $1(1-2)$ & $2.2(1-3.5)$ & .07 \\
\hline Diabetes, $n(\%)$ & $71(61.7)$ & $50(64.1)$ & $21(56.8)$ & .39 \\
\hline Hypertension, $n(\%)$ & $90(78.3)$ & $61(78.2)$ & $29(78.4)$ & .98 \\
\hline Dyslipidemia, $n(\%)$ & $27(23.5)$ & $21(26.9)$ & $6(16.2)$ & .21 \\
\hline HFrEF, $n(\%)$ & $11(9.6)$ & $7(9)$ & $4(10.8)$ & .75 \\
\hline $\mathrm{PAD}, n(\%)$ & $7(6.1)$ & $4(5.1)$ & $3(8.1)$ & .53 \\
\hline Pulmonary hypertension, $n(\%)$ & $26(22.6)$ & $15(19.2)$ & $11(29.7)$ & .21 \\
\hline OSAS, $n(\%)$ & $83(72.2)$ & $55(70.5)$ & $28(75.7)$ & .56 \\
\hline OSAS severity & & & & .82 \\
\hline Mild, $n(\%)$ & $5(6)$ & $3(5.4)$ & $2(5.4)$ & NA \\
\hline Moderate, $n(\%)$ & $19(22.8)$ & $12(21.8)$ & $7(18.9)$ & NA \\
\hline Severe, $n(\%)$ & $59(71)$ & 40 (72.7) & $19(51.3)$ & NA \\
\hline AHI, median (range) & $40(25-62)$ & $41(25-64)$ & $43(25-56)$ & .59 \\
\hline \multicolumn{5}{|l|}{ Treatment } \\
\hline CPAP, $n(\%)$ & $21(18.4)$ & $14(17.9)$ & 7 (18.9) & .78 \\
\hline $\mathrm{NIV}, n(\%)$ & 89 (77.4) & $63(80.8)$ & $26(70.3)$ & .21 \\
\hline IPAP, median (range) & $20(17-21)$ & $20(17-21)$ & $19(18-21)$ & .37 \\
\hline EPAP, median (range) & $8(7-10)$ & $8(7-10)$ & $8(7-9)$ & .63 \\
\hline LTOT, $n(\%)$ & $43(37.4)$ & $30(38.5)$ & $13(35.1)$ & .72 \\
\hline No treatment, $n(\%)$ & $6(5.2)$ & $3(3.8)$ & $3(8.1)$ & .33 \\
\hline \multicolumn{5}{|l|}{ ABG, median (range) } \\
\hline \multicolumn{5}{|l|}{ At OHS diagnosis } \\
\hline $\mathrm{pH}$, median (range) & $7.38(7.36-7.40)$ & $7.38(7.36-7.40)$ & $7.38(7.36-7.42)$ & .89 \\
\hline $\mathrm{P}_{\mathrm{aCO}_{2}}, \mathrm{~mm} \mathrm{Hg}$ & $49(47-53)$ & $49(47-52)$ & $51(48-53)$ & .13 \\
\hline Bicarbonate, $\mathrm{mmol} / \mathrm{L}$ & $29(27-31)$ & $29(27-31)$ & $30(28-31)$ & .13 \\
\hline \multicolumn{5}{|l|}{ At the last evaluation } \\
\hline $\mathrm{pH}$ & $7.40(7.38-7.42)$ & $7.40(7.38-7.42)$ & $7.40(7.36-7.40)$ & .051 \\
\hline $\mathrm{P}_{\mathrm{aCO}_{2}}, \mathrm{~mm} \mathrm{Hg}$ & $45(40-47)$ & $44(40-46)$ & $45(40-48)$ & .26 \\
\hline \multicolumn{5}{|l|}{ PFT at diagnosis, median (range) $\%$} \\
\hline $\mathrm{FEV}_{1} / \mathrm{FVC}$ & $75(71-80)$ & $75(72-80)$ & $75(70-79)$ & .45 \\
\hline $\mathrm{FEV}_{1}$ & $73(63-85)$ & $75(67-90)$ & $65(58-76)$ & .004 \\
\hline $\mathrm{FVC}$ & $77(68-90)$ & $80(70-96)$ & $72(65-80)$ & .01 \\
\hline TLC & 85 (76-95) & 88 (77-98) & $82(73-92)$ & .062 \\
\hline Mortality, $n(\%)$ & $20(17.4)$ & $11(14.1)$ & $9(24.3)$ & .17 \\
\hline Cause of death, $n(\%)$ & & & & .49 \\
\hline OHS & $6(5.2)$ & $5(6.4)$ & $1(2.7)$ & NA \\
\hline Cancer & $5(4.3)$ & $2(2.5)$ & $3(8.1)$ & NA \\
\hline Stroke & $4(3.4)$ & $2(2.5)$ & $2(5.4)$ & NA \\
\hline Septic shock & $2(1.7)$ & $1(1.2)$ & $1(2.7)$ & NA \\
\hline Unknown & $3(2.6)$ & $1(1.2)$ & $2(5.4)$ & NA \\
\hline
\end{tabular}


Table 1. Continued

\begin{tabular}{|c|c|c|c|c|}
\hline \multirow[b]{2}{*}{ Characteristic } & \multicolumn{3}{|c|}{ OHS } & \multirow[b]{2}{*}{$P$} \\
\hline & $\begin{array}{l}\text { Overall Population } \\
\quad(N=115)\end{array}$ & $\begin{array}{l}\text { Without ICU Admission } \\
\qquad(n=78)\end{array}$ & $\begin{array}{l}\text { With ICU Admission } \\
\qquad(n=37)\end{array}$ & \\
\hline Follow-up length, median (range) y & $3.5(1.4-6)$ & $3.4(1.6-6.8)$ & $3.3(1.3-4.5)$ & .23 \\
\hline
\end{tabular}

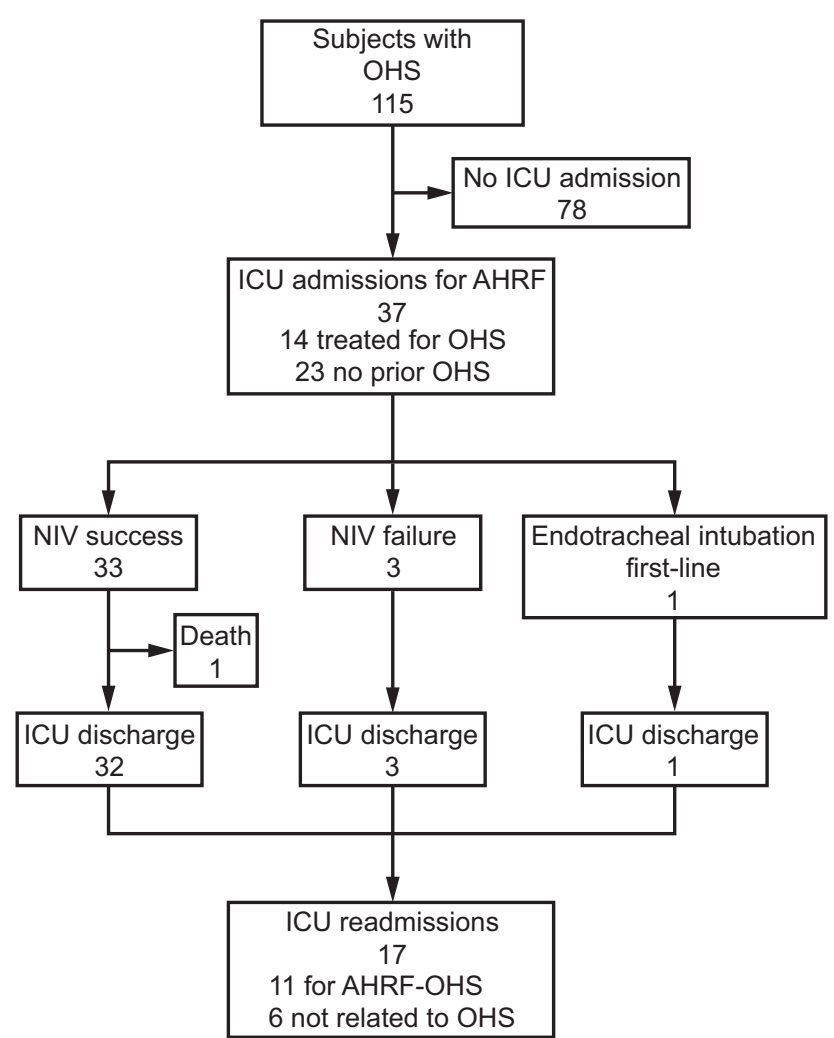

Fig. 1. Flow chart. OHS = obesity hypoventilation syndrome, NIV = nonivasive ventilation, AHRF = acute hypercapnic respiratory failure.

(Fig. 1, Table 1). At the time of ICU admission, frequency was median (range) $25(20-30)$ breaths/min, $\mathrm{pH}$ was 7.26 (7.22-7.31), and $\mathrm{P}_{\mathrm{aCO}}$ was 70 (61-76) $\mathrm{mm} \mathrm{Hg}$ before any NIV use (Table 2). The most frequent precipitating factor of acute hypercapnic respiratory failure was congestive heart failure (54\%), followed by acute pulmonary embolism $(10.8 \%)$. Acute-on-chronic respiratory failure secondary to OHS without any identified precipitating factor occurred in the remaining 11 subjects $(29.7 \%)$ (Table 2). Fourteen subjects $(37.8 \%)$ were diagnosed with OHS and were treated with CPAP or home NIV before ICU admission.

For subjects with home NIV, an initial trial of their device was made. In case of clinical or gas exchange wors- ening, a switch to an ICU ventilator was done with pressure support ventilation. For subjects without home NIV, an ICU ventilator with pressure support ventilation was used at admission, then subsequently switched to NIV before referral to pneumology wards. Among the 23 subjects without a known OHS diagnosis before ICU admission, $7(30 \%)$ were hospitalized in medical wards at least once during the previous $2 \mathrm{y}$ for respiratory or non-respiratory purposes. During the ICU stay, NIV was used as first-line ventilatory support in 36 subjects $(97.2 \%)$ and was successful in 33 subjects (91.7\%) (Table 2). The time to correct hypercapnic acidosis with NIV was median (range) 2.9 (1-3) d. Invasive ventilation was used as a first-line respiratory support in 1 subject $(2.7 \%)$ and after NIV failure in 3 subjects (8.3\%). The cause of NIV failure was worsening mental status in 2 subjects and severe hypoxemia with acute respiratory distress syndrome in 1 subject due to infectious pneumonia. No serious complications of NIV use were reported. These 23 subjects (62.1\%), who had no OHS diagnosis before ICU admission (and who were not treated with home ventilatory support), were transferred from the ICU to the pneumology department with an NIV device. Only one subject (2.7\%) died in the ICU. The cause of death was not related to respiratory failure but to an ulterior palliative care decision for metastatic ovarian cancer. ICU and hospital length of stay were median (range) $7.2(4-8) \mathrm{d}$ and $14.2(10-16.5) \mathrm{d}$, respectively (Table 2). After ICU discharge, 17 subjects $(45.9 \%)$ were readmitted to the ICU after a median period of median (range) $0.8(0.2-1.8)$ y, among whom, 11 (29.7\%) had acute hypercapnic respiratory failure related to $\mathrm{OHS}$ (Fig. 1).

\section{Comparison Between Subjects With and Without ICU Admission}

The subjects with OHS who were admitted to the ICU for acute hypercapnic respiratory failure were older and had lower $\mathrm{FEV}_{1}$ and lower vital capacity (VC) at the time of the OHS diagnosis than those not admitted to the ICU (Table 1). There was no significant difference between the 2 groups for BMI, sex ratio, comorbidities, frequency of 
Table 2. Clinical, Biological, and Treatment Characteristics of Subjects With OHS Admitted to the ICU

\begin{tabular}{|c|c|}
\hline Characteristic & OHS in the ICU \\
\hline Age at ICU admission, median (range) y & $71(65-78)$ \\
\hline \multicolumn{2}{|l|}{$\begin{array}{l}\text { ABG, plasma bicarbonate, and lactate at ICU } \\
\text { admission (before NIV use), median (range) }\end{array}$} \\
\hline $\mathrm{pH}$ & $7.26(7.22-7.31)$ \\
\hline $\mathrm{P}_{\mathrm{aCO}_{2}} \mathrm{~mm} \mathrm{Hg}$ & $70(61-76)$ \\
\hline $\mathrm{P}_{\mathrm{aO}_{2}} \mathrm{~mm} \mathrm{Hg}$ & $79(66-83)$ \\
\hline Bicarbonate, $\mathrm{mmol} / \mathrm{L}$ & $30(26-35)$ \\
\hline Lactate, $\mathrm{mmol} / \mathrm{L}$ & $1.2(0.8-1.7)$ \\
\hline \multicolumn{2}{|l|}{ Vital signs, median (range) } \\
\hline Mean arterial pressure, $\mathrm{mm} \mathrm{Hg}$ & $81(66-95)$ \\
\hline Heart rate, beats/min & $91(80-95)$ \\
\hline Breathing frequency, breaths/min & $25(20-30)$ \\
\hline Glasgow coma score & $13(13-15)$ \\
\hline SAPS II score & $36(23-49)$ \\
\hline \multicolumn{2}{|l|}{ AHRF cause, $n(\%)$} \\
\hline Congestive heart failure & $20(54)$ \\
\hline OHS & $11(29.7)$ \\
\hline Pulmonary embolism & $4(10.8)$ \\
\hline Pneumonia & $1(2.7)$ \\
\hline Neoplastic pleural effusion & $1(2.7)$ \\
\hline \multicolumn{2}{|l|}{ OHS diagnosis } \\
\hline Previous diagnosis, $n(\%)$ & $14(37.8)$ \\
\hline $\begin{array}{l}\text { Delayed diagnosis-ICU admission, median } \\
\text { (range) mo }\end{array}$ & $11.5(-2.4$ to 25$)$ \\
\hline \multicolumn{2}{|l|}{ Treatment } \\
\hline NIV first line, $n(\%)$ & $36(97.2)$ \\
\hline NIV success, $n(\%)$ & $33(91.7)$ \\
\hline Invasive ventilation first line, $n(\%)$ & $1(2.7)$ \\
\hline Invasive ventilation after NIV failure, $n(\%)$ & $3(8.1)$ \\
\hline $\begin{array}{l}\text { Duration of invasive ventilation, median } \\
\text { (range) } d\end{array}$ & $4.4(1-7)$ \\
\hline Duration of NIV, median (range) d & $6(3-8)$ \\
\hline $\begin{array}{l}\text { Time to correct acidosis with NIV, median } \\
\text { (range) d }\end{array}$ & $2.9(1-3)$ \\
\hline NIV at ICU discharge, $n(\%)$ & $23(62.1)$ \\
\hline Renal dialysis, $n(\%)$ & $3(8.1)$ \\
\hline Vasopressor agents, $n(\%)$ & $8(21.6)$ \\
\hline \multicolumn{2}{|l|}{ Length of stay, $d$} \\
\hline ICU, median (range) & $7.2(4-8)$ \\
\hline After ICU, median (range) & $14.2(10-16.5)$ \\
\hline Death in the ICU, $n(\%)$ & $1(2.7)$ \\
\hline \multicolumn{2}{|l|}{$\begin{array}{l}\text { OHS }=\text { Obesity-hypoventilation syndrome } \\
\text { ABG = = arterial blood gas } \\
\text { NIV = noninvasive ventilation } \\
\text { SAPS II = Simplified Acute Phyiology Score II } \\
\text { AHRF = acute hypercapnic respiratory failure }\end{array}$} \\
\hline
\end{tabular}

OSAS, type of home ventilatory support, or arterial blood gas. Overall survival tended to be significantly lower in the subjects with than in those without ICU admission $(P=.051)$ (Fig. 2). The restricted mean survival time was significant, with a gain in survival of $663(95 \%$ CI 69$1,256) \mathrm{d}$ for those subjects not admitted to the $\mathrm{ICU}(P=.03)$.
The survival rates at 1,3 , and $5 \mathrm{y}$ were $100,92.5$, and $85.7 \%$, respectively, for the subjects without ICU admission, and were $97,89.7$, and $65.3 \%$, respectively, for those admitted to the ICU.

\section{Factors Associated With ICU Admission}

Age, BMI, VC, and $\mathrm{PaCO}_{2}$ at the time of the OHS diagnosis were significantly associated with ICU admission in the univariate analysis (Table 3). Multivariate analysis showed that only VC at the OHS diagnosis was independently associated with the risk of ICU admission (Hazard ratio $0.92,95 \% \mathrm{CI} 0.86-0.97 ; P=.007)$, the higher the $\mathrm{VC}$, the lower the risk of ICU admission (Table 3).

\section{Factors Associated With Long-Term Outcome}

Age at diagnosis, $\mathrm{VC}$ at diagnosis, $\mathrm{P}_{\mathrm{aCO}_{2}}$ of $>50 \mathrm{~mm} \mathrm{Hg}$ at diagnosis, and heart failure with reduced ejection fraction and ICU admission over the course of the disease were significantly associated with overall mortality in the univariate analysis (Table 4). However, the Cox proportional hazard model did not find any factor significantly associated with overall mortality in the multivariate analysis (Table 4).

\section{Role of the ICU Stay on Long-Term Survival}

The hypothesis of proportionality of risk of an ICU stay was not rejected $(P=.85)$, and the ICU stay was not significantly associated with long-term outcome $(P=.81)$. This was also found with the Cox model for time-dependent covariates $(P=.17)$.

\section{Discussion}

The main findings of the present study can be summarized as follows:

- Congestive heart failure was the leading cause of acute hypercapnic respiratory failure $(>50 \%)$ in the subjects with OHS.

- Despite the severity of respiratory acidosis, NIV was an effective first-line treatment in nearly $90 \%$ of subjects.

- Lower VC at the time of OHS diagnosis was associated with a higher risk of ICU admission. ICU admission was not significantly associated with long-term outcome; however, the subjects not admitted to the ICU had a significant gain in survival, of $663 \mathrm{~d}$.

OHS is still an unrecognized and misdiagnosed condition, despite the increasing prevalence of obesity all over the world. ${ }^{15}$ OHS is found in up to $20 \%$ of patients who are obese and with OSAS, and its rate increases with higher 


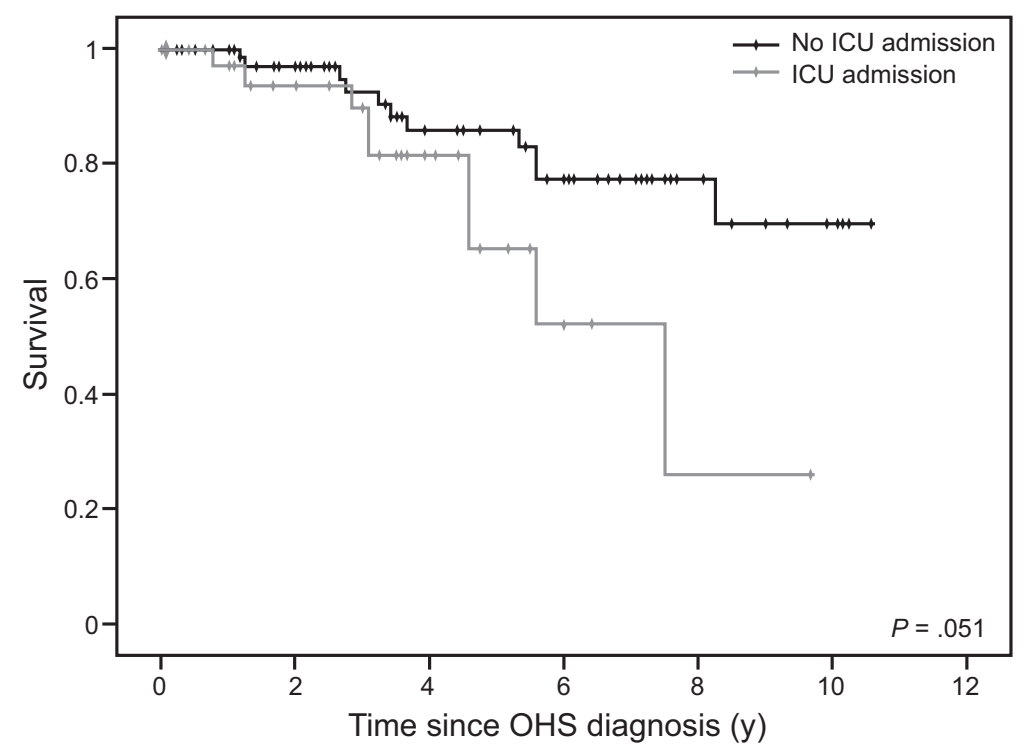

\begin{tabular}{|c|c|c|c|c|c|}
\hline No ICU admission & 78 & 56 & 35 & 25 & 10 \\
\hline ICU admission & 37 & 25 & 13 & 3 & 1 \\
\hline
\end{tabular}

Fig. 2. Survival of OHS patients according to ICU admission. OHS = obesity-hypoventilation syndrome, ICU = intensive care unit.

Table 3. Uni- and Multivariate Analysis of Factors Associated With ICU Admission for Subjects With OHS Using Logistic Regression

\begin{tabular}{|c|c|c|c|c|}
\hline \multirow{2}{*}{ Factor } & \multicolumn{2}{|c|}{ Univariate Analysis } & \multicolumn{2}{|c|}{ Multivariate Analysis } \\
\hline & $P$ & HR $(95 \% \mathrm{CI})$ & $P$ & $\mathrm{HR}(95 \% \mathrm{CI})$ \\
\hline Age at diagnosis, $\mathrm{y}$ & .01 & $1.05(1.01-1.09)$ & .36 & $1.03(0.95-1.12)$ \\
\hline BMI at diagnosis, $\mathrm{kg} / \mathrm{m}^{2}$ & .15 & $0.96(0.92-1.01)$ & .25 & $0.93(0.82-1.05)$ \\
\hline $\mathrm{FVC}$ at diagnosis, $\%$ & .05 & $0.95(0.92-0.98)$ & .007 & $0.92(0.86-0.97)$ \\
\hline $\mathrm{P}_{\mathrm{aCO}_{2}}$ at diagnosis, $\mathrm{mm} \mathrm{Hg}$ & .11 & $1.07(0.98-1.16)$ & .63 & $1.03(0.89-1.20)$ \\
\hline $\begin{array}{l}\mathrm{HR}=\text { hazard ratio } \\
\mathrm{BMI}=\text { body mass index }\end{array}$ & & & & \\
\hline
\end{tabular}

BMI. ${ }^{16-21}$ Epidemiological studies ${ }^{5,22-24}$ that report the prevalence of OHS in hospitalized subjects and particularly in the ICU setting are lacking. One study reported a $31 \%$ prevalence of OHS among adult hospitalized subjects with obesity (BMI threshold of $30 \mathrm{~kg} / \mathrm{m}^{2}$ ). ${ }^{22}$ Another study conducted in an ICU found that $8 \%$ of all admissions fulfilled the diagnostic criteria for OHS (BMI threshold of $40 \mathrm{~kg} / \mathrm{m}^{2}$ ). ${ }^{5}$ In our study, $32 \%$ of the subjects with OHS were admitted to the ICUs for acute hypercapnic respiratory failure and $46 \%$ of them were readmitted for the same reasons in the following 2 years.

Interestingly, $62 \%$ of the subjects admitted to the ICU had no previous diagnosis of OHS, and 30\% of the subjects had no additional cause for acute hypercapnic respiratory failure besides OHS. This finding was consistent with other studies in which OHS was revealed by severe acute hyper- capnic respiratory failure that required ventilatory support. ${ }^{23-26}$ Moreover, the fact that one third of the subjects were hospitalized in the previous 2 years for respiratory or non-respiratory purposes highlights the risks of delay in making a diagnosis of OHS in these patients. After ICU discharge, as well as after hospital discharge, all the subjects with no previous diagnosis of OHS were treated with domiciliary CPAP or NIV, and the OHS diagnosis was confirmed after a median delay of median (range) 0.9 (0.6-3.5) months.

Another finding of our study was the burden of congestive heart failure in subjects with OHS and with acute hypercapnic respiratory failure. Cardiovascular comorbidities are frequent in patients who are obese. ${ }^{27}$ Although the diagnosis of heart failure with altered ejection fraction is relatively easy to make, that of heart failure with preserved heart systolic function can be difficult. Left-ventricular 


\section{Acute Respiratory FaILURe in OHS}

Table 4. Uni- and Multivariate Analysis of Factors Associated With Overall Mortality for Subjects With OHS Using the Cox Proportional Hazard Model

\begin{tabular}{|c|c|c|c|c|}
\hline \multirow{2}{*}{ Factor } & \multicolumn{2}{|c|}{ Univariate Analysis } & \multicolumn{2}{|c|}{ Multivariate Analysis } \\
\hline & $P$ & $\operatorname{HR}(95 \% \mathrm{CI})$ & $P$ & HR $(95 \%$ CI $)$ \\
\hline Age at diagnosis, $\mathrm{y}$ & .059 & $1.05(0.99-1.11)$ & .14 & $1.04(0.98-1.11)$ \\
\hline HFrEF & .09 & $2.52(0.84-7.58)$ & .13 & $2.45(0.74-8.08)$ \\
\hline FVC & .04 & $0.96(0.92-1.00)$ & .14 & $0.96(0.92-1.01)$ \\
\hline $\mathrm{P}_{\mathrm{aCO}_{2}}$ at diagnosis $>50 \mathrm{~mm} \mathrm{Hg}$ & .07 & $2.49(0.90-6.8)$ & .11 & $2.77(0.78-9.84)$ \\
\hline ICU admission & .07 & $2.26(0.91-5.64)$ & .92 & $0.94(0.30-2.94)$ \\
\hline \multicolumn{5}{|l|}{$\overline{\mathrm{HR}=\text { hazard ratio }}$} \\
\hline
\end{tabular}

diastolic dysfunction is a known complication of obesity. ${ }^{27}$ In addition, pulmonary hypertension is another important clinical feature of OHS. ${ }^{28,29}$ Therefore, patients with OHS need a careful examination of heart function and loading conditions. Interestingly, NIV use in patients with OHS can improve pulmonary hemodynamics by correcting chronic hypoventilation. ${ }^{28-31}$ Pulmonary embolism and pneumonia were listed as causes of acute hypercapnic respiratory failure and result in mixed hypoxemic and hypercapnic respiratory failure. Due to the retrospective nature of our study, evaluating the burden of preexisting OHS and that of specific precipitating factors in the setting of acute respiratory failure was difficult.

In our study, NIV had a very high success rate to treat acute hypercapnic respiratory failure (91\%). Studies that evaluated NIV in subjects who were obese and critically ill found NIV failure rates that ranged from 2 to $60 \% .^{23,32-36}$ The higher failure rates in these studies than in the current study may be explained by higher severity scores, more severe hypoxemia, and infectious pneumonia as the main reason for acute hypercapnic respiratory failure. ${ }^{36}$ Higher NIV success rates were found in subjects with acute idiopathic decompensation of OHS and with high $\mathrm{P}_{\mathrm{aCO}_{2}}$ levels. ${ }^{33,36}$ Interestingly, subjects with acute-on-chronic respiratory failure had a delayed but successful response to prolonged NIV, which prevented intubation. ${ }^{33,36}$ In our study, the median time to correct respiratory acidosis with NIV was $2.9 \mathrm{~d}$, which should encourage the prolonged use of NIV when this is possible, instead of early intubation. This delay may be explained by the high initial $\mathrm{P}_{\mathrm{aCO}_{2}}$ in our subjects and the reduced neural respiratory drive found in patients with OHS. ${ }^{37,38}$

We identified lower VC at the time of the OHS diagnosis as a factor independently associated with ICU admission for acute hypercapnic respiratory failure. Lower values of $\mathrm{VC}$ are found in hypercapnic compared with patients who are eucapnic and who are obese and with OSAS. ${ }^{39}$ This finding indicated that a restrictive pattern on pulmonary function tests might be considered as a surrogate marker of OHS severity.

Our study was one of the few studies to report long-term survival in subjects with OHS. We found a 5-y survival rate of $80 \%$ and a $10-y$ survival rate of $60 \%$. These findings were similar to survival rates reported in previous studies. ${ }^{25,40}$ We found no independent factor associated with long-term overall mortality. The ICU mortality rate in our study $(2.7 \%)$ was lower than predicted by the Simplified Acute Physiology Score II score of $18 \%$. Even though the subjects admitted to the ICU tended to a have a higher overall mortality rate, no causality effect could be drawn from this observation. This finding, along with the low ICU mortality rate, suggested that referral of patients with OHS and acute hypercapnic respiratory failure to ICUs remains justified. The difference in the restricted mean survival time showed that the subjects without an ICU stay survived longer than the subjects who stayed in the ICU. This was an expected result. However, we were unable to show that an ICU stay is a risk factor for the long-term outcome in the multivariate analyses we performed. This discrepancy could be due to the lack of power of our study.

Our study had several limitations. Due to its retrospective nature, the selection and information bias may have underestimated the real prevalence of OHS in the ICU because we only included subjects with an established diagnosis of OHS and may have excluded undiagnosed cases. This also prevented us from analyzing the effect of the NIV interface on gas exchange correction and outcome. Another limitation was the monocentric design of our study, which may have hindered the extrapolation of results. However, our OHS population was comparable with other OHS cohorts reported in the literature with regard to BMI, frequency of OSAS, arterial blood gas, and hypoventilation management.5,23,26 Moreover, the small sample size and the relatively low number of events (ICU admissions or deaths) made our study underpowered. 


\section{Acute Respiratory Failure in OHS}

\section{Conclusions}

Our study showed that acute hypercapnic respiratory failure that required ICU admission in subjects with OHS was generally responsive to NIV and had favorable outcomes. A thorough diagnostic and therapeutic workup for congestive heart failure was necessary because of the heavy burden of cardiovascular diseases in this setting. Undiagnosed OHS was present in nearly two thirds of the subjects admitted to the ICU, which highlighted the need for increased awareness to better recognize OHS and prevent its respiratory complications.

\section{REFERENCES}

1. Sleep-related breathing disorders in adults: recommendations for syndrome definition and measurement techniques in clinical research. The Report of an American Academy of Sleep Medicine Task Force. Sleep 1999;22(5):667-689.

2. Hruby A, Hu FB. The epidemiology of obesity: a big picture. Pharmacoeconomics 2015;33(7):673-689.

3. Williams EP, Mesidor M, Winters K, Dubbert PM, Wyatt SB. Overweight and obesity: prevalence, consequences, and causes of a growing public health problem. Curr Obes Rep 2015;4(3):363-370.

4. Arroyo-Johnson C, Mincey KD. Obesity epidemiology worldwide. Gastroenterol Clin North Am 2016;45(4):571-579.

5. Marik PE, Desai H. Characteristics of patients with the "malignant obesity hypoventilation syndrome" admitted to an ICU. J Intensive Care Med 2013;28(2):124-130.

6. Akinnusi ME, Pineda LA, El Solh AA. Effect of obesity on intensive care morbidity and mortality: a meta-analysis. Crit Care Med 2008; 36(1):151-158.

7. Oliveros H, Villamor E. Obesity and mortality in critically ill adults: a systematic review and meta-analysis. Obesity 2008;16(3):515-521.

8. Antonelli M, Conti G, Rocco M, Bufi M, De Blasi RA, Vivino G, et al. A comparison of noninvasive positive-pressure ventilation and conventional mechanical ventilation in patients with acute respiratory failure. N Engl J Med 1998;339(7):429-435.

9. Liu YJ, Zhao J, Tang H. Non-invasive ventilation in acute respiratory failure: a meta-analysis. Clin Med (Lond) 2016;16(6):514-523.

10. Masip J, Roque M, Sánchez B, Fernández R, Subirana M, Expósito JA. Noninvasive ventilation in acute cardiogenic pulmonary edema: systematic review and meta-analysis. JAMA 2005;294(24):31243130.

11. Cabrini L, Landoni G, Oriani A, Plumari VP, Nobile L, Greco M, et al. Noninvasive ventilation and survival in acute care settings: a comprehensive systematic review and metaanalysis of randomized controlled trials. Crit Care Med 2015;43(4):880-888.

12. Hilbert G, Gruson D, Vargas F, Valentino R, Gbikpi-Benissan G, Dupon M, et al. Noninvasive ventilation in immunosuppressed patients with pulmonary infiltrates, fever, and acute respiratory failure. N Engl J Med 2001;344(7):481-487.

13. Wang T, Zhang L, Luo K, He J, Ma Y, Li Z, et al. Noninvasive versus invasive mechanical ventilation for immunocompromised patients with acute respiratory failure: a systematic review and metaanalysis. BMC Pulm Med 2016;16(1):129.

14. Davidson AC, Banham S, Elliott M, Kennedy D, Gelder C, Glossop A, et al.; BTS Standards of Care Committee Member, British Thoracic Society/Intensive Care Society Acute Hypercapnic Respiratory Failure Guideline Development Group, On behalf of the British Thoracic Society Standards of Care Committee. BTS/ICS guideline for the ventilatory management of acute hypercapnic respiratory failure in adults. Thorax 2016;71(Suppl 2):ii1-35.

15. Kaw R, Bhateja P, Paz Y Mar H, Hernandez AV, Ramaswamy A, Deshpande A, Aboussouan LS. Postoperative complications in patients with unrecognized obesity hypoventilation syndrome undergoing elective noncardiac surgery. Chest 2016;149(1):84-91.

16. Verin E, Tardif C, Pasquis P. Prevalence of daytime hypercapnia or hypoxia in patients with OSAS and normal lung function. Respir Med 2001;95(8):693-696.

17. Laaban JP, Chailleux E. Daytime hypercapnia in adult patients with obstructive sleep apnea syndrome in France, before initiating nocturnal nasal continuous positive airway pressure therapy. Chest 2005; 127(3):710-715.

18. Kessler R, Chaouat A, Schinkewitch P, Faller M, Casel S, Krieger J, Weitzenblum E. The Obesity-hypoventilation syndrome revisited: a prospective study of 34 consecutive cases. Chest 2001;120(2):369376.

19. Golpe R, Jiménez A, Carpizo R. Diurnal hypercapnia in patients with obstructive sleep apnea syndrome. Chest 2002;122(3):1100-1101; author reply 1101 .

20. Akashiba T, Akahoshi T, Kawahara S, Uematsu A, Katsura K, Sakurai $\mathrm{S}$, et al. Clinical characteristics of Obesity-hypoventilation syndrome in Japan: a multi-center study. Intern Med 2006;45(20):11211125.

21. Mokhlesi B, Tulaimat A, Faibussowitsch I, Wang Y, Evans AT. Obesity hypoventilation syndrome: prevalence and predictors in patients with obstructive sleep apnea. Sleep Breath 2007;11(2):117124 .

22. Nowbar S, Burkart KM, Gonzales R, Fedorowicz A, Gozansky WS, Gaudio JC, et al. Obesity-associated hypoventilation in hospitalized patients: prevalence, effects, and outcome. Am J Med 2004;116(1): $1-7$.

23. Carrillo A, Ferrer M, Gonzalez-Diaz G, Lopez-Martinez A, Llamas $\mathrm{N}$, Alcazar M, et al. Noninvasive ventilation in acute hypercapnic respiratory failure caused by obesity hypoventilation syndrome and chronic obstructive pulmonary disease. Am J Respir Crit Care Med 2012;186(12):1279-1285.

24. Bry C, Jaffré S, Guyomarc'h B, Corne F, Chollet S, Magnan A, Blanc FX. Noninvasive ventilation in obese subjects after acute respiratory failure. Respir Care 2018;63(1):28-35.

25. Priou P, Hamel JF, Person C, Meslier N, Racineux JL, Urban T, Gagnadoux F. Long-term outcome of noninvasive positive pressure ventilation for obesity hypoventilation syndrome. Chest 2010;138(1): 84-90.

26. Marik PE, Chen C. The clinical characteristics and hospital and post-hospital survival of patients with the obesity hypoventilation syndrome: analysis of a large cohort. Obes Sci Pract 2016;2(1): 40-47.

27. Alpert MA, Lavie CJ, Agrawal H, Aggarwal KB, Kumar SA. Obesity and heart failure: epidemiology, pathophysiology, clinical manifestations, and management. Transl Res 2014;164(4):345-356.

28. Atwood CW Jr, McCrory D, Garcia JG, Abman SH, Ahearn GS; American College of Chest Physicians. Pulmonary artery hypertension and sleep-disordered breathing: ACCP evidence-based clinical practice guidelines. Chest 2004;126(1 Suppl):72S-77S.

29. Kauppert CA, Dvorak I, Kollert F, Heinemann F, Jörres RA, Pfeifer M, Budweiser S. Pulmonary hypertension in Obesity-hypoventilation syndrome. Respir Med 2013;107(12):2061-2070.

30. Held M, Walthelm J, Baron S, Roth C, Jany B. Functional impact of pulmonary hypertension due to hypoventilation and changes under noninvasive ventilation. Eur Respir J 2014;43(1):156-165.

31. Cottin V, Lorillou M, Khouatra C, Traclet J, Nesme P, Cordier JF. Pulmonary hypertension-specific therapy in patients with chronic respiratory insufficiency. Eur Respir J 2014;44(3):819-821. 


\section{Acute Respiratory FaILURe in OHS}

32. Gursel G, Aydogdu M, Tasyurek S, Gulbas G, Ozkaya S, Nazik S, Demir A. Factors associated with noninvasive ventilation response in the first day of therapy in patients with hypercapnic respiratory failure. Ann Thorac Med 2012;7(2):92-97.

33. Lemyze M, Taufour P, Duhamel A, Temime J, Nigeon O, Vangrunderbeeck N, et al. Determinants of noninvasive ventilation success or failure in morbidly obese patients in acute respiratory failure. PloS One 2014;9(5):e97563.

34. Gursel G, Aydogdu M, Gulbas G, Ozkaya S, Tasyurek S, Yildirim F. The influence of severe obesity on non-invasive ventilation (NIV) strategies and responses in patients with acute hypercapnic respiratory failure attacks in the ICU. Minerva Anestesiol 2011;77(1):17-25.

35. Contou D, Fragnoli C, Córdoba-Izquierdo A, Boissier F, Brun-Buisson C, Thille AW. Noninvasive ventilation for acute hypercapnic respiratory failure: intubation rate in an experienced unit. Respir Care 2013;58(12):2045-2052.
36. Nicolini A, Lemyze M, Esquinas A, Barlascini C, Cavalleri MA. Predictors of noninvasive ventilation failure in critically ill obese patients: a brief narrative review. Adv Respir Med 2017;85(5):264270.

37. Sequeira TCA, BaHammam AS, Esquinas AM. Noninvasive ventilation in the critically ill patient with obesity hypoventilation syndrome: a review. J Intensive Care Med 2017;32(7):421-428.

38. Jones SF, Brito V, Ghamande S. Obesity hypoventilation syndrome in the critically ill. Crit Care Clin 2015;31(3):419-434.

39. Mokhlesi B. Obesity hypoventilation syndrome: a state-of-the-art review. Respir Care 2010;55(10):1347-1362; discussion 13631365.

40. Budweiser S, Riedl SG, Jörres RA, Heinemann F, Pfeifer M. Mortality and prognostic factors in patients with Obesity-hypoventilation syndrome undergoing noninvasive ventilation. J Intern Med 2007; 261(4):375-383. 